\title{
Escasez de agua: develando sus orígenes híbridos en la cuenca del Río Bueno, Chile
}

\author{
Water scarcity: disclosing its hybrid origins \\ in the Bueno river basin, Chile
}

\author{
Oppliger, Astrid'; Höhl, Johanna² y Fragkou, María ${ }^{3}$
}

\begin{abstract}
RESUMEN
Este articulo examina los orígenes sociales de la escasez de agua en la cuenca del rio Bueno, Chile. Se emplea el marco teórico de la ecología política para analizar la escasez hídrica como un fenómeno "híbrido" de carácter socionatural, destacando el desarrollo de un marco de "tipologías de escasez de agua". Utilizando una metodología mixta, analizamos datos hídricos cuantitativos y cualitativos para develar las tipologías de escasez de agua existentes, quién sufre de escasez hídrica y a qué factores se atribuye esta. Nuestros resultados demuestran la existencia de diversas tipologías de escasez de agua y que la escasez hídrica no afecta a todos los actores, hechos que revelan factores antrópicos en su producción. Concluimos que los orígenes de la escasez de agua son múltiples y que la gestión del agua en Chile ha priorizando las actividades económicas de alto interés nacional por sobre el agua para consumo humano.
\end{abstract}

Palabras claves: Escasez de agua, ecología política, gestión de agua, plantaciones forestales, Chile.

\begin{abstract}
The current article examines the social origins of water scarcity in Rio Bueno basin, Chile. The political ecology's theoretical framework is employed to assess water scarcity as an "hybrid" phenomenon of socionatural nature, highlighting the development of a frame of "water scarcity typologies". By employing a combined methodology, we analyzed quantitative and qualitative water related data to reveal the existing water scarcity typologies, who suffers from water scarcity as well as to which factors this scarcity is attributed. Our results demonstrate the existence of different water scarcity typologies, and that water scarcity does not affect all actors involved, thus revealing anthropological factors in its production. We conclude that the origins of water scarcity are multiple, and that water management in Chile has prioritized economic activities of high national interest over the use of water for human consumption.
\end{abstract}

Key words: Water scarcity, political ecology, water management, forest plantations, Chile. 


\section{Introducción}

En los últimos años Chile está experimentando una alteración en sus precipitaciones, atribuida a una macrosequía que data desde el año 2008 (CR2, 2015). La situación ha sido reconocida por el actual gobierno como uno de los principales problemas que enfrenta el país (Bachelet, 2015), y su extensión ha afectado incluso a regiones como la de los Ríos, que tradicionalmente han tenido abundantes precipitaciones y caudales (DGA, 2016).

El Estado central atribuye la escasez de agua principalmente al cambio climático y la reducción de las precipitaciones, y sus medidas de índole institucional, infraestructural y tecnológico, son orientadas casi exclusivamente a aumentar la disponibilidad de la oferta hídrica (Bachelet, 2015). Por lo que, posibles causas antrópicas de la escasez de agua, tales como las dimensiones estructurales, de gestión, o de distribución de los recursos hídricos no son consideradas.

En este artículo, desafiamos la naturalización discursiva de los orígenes de la escasez de agua y la reconocemos como un fenómeno de naturaleza híbrida (Swyngedouw, 2009), que responde a orígenes tanto físicos como sociales que la construyen. Argumentamos que el Estado en su nivel central se desvincula de las realidades locales al invisibilizar los factores antrópicos de la escasez de agua. Asimismo, se desconecta conceptualmente al definir la escasez de agua únicamente en base a indicadores físicos, que muchas veces no responden a las realidades locales de territorios donde las precipitaciones y caudales no están gravemente reducidas, pero la existencia de factores antrópicos invisibilizados de igual forma construyen escasez de agua, impactando a otros actores relevantes en el territorio.

Para entender cómo se produce y qué implicancias tiene la desarticulación escalar y conceptual de la escasez de agua, indagamos posicionadas desde la ecología política, en develar los orígenes híbridos de la escasez mediante un esquema de tipologías de escasez de agua, que sintetiza el trabajo de diversas disciplinas (Oppliger, 2016). Para demostrar la construcción social de la escasez de agua, tomamos como caso de estudio la sección baja de la cuenca del Río Bueno, al oeste de la comuna de La Unión, en la Región de los Ríos. Dicha zona resulta interesante de analizar para cuestionar la naturalización de la escasez de agua e indagar en sus distintas causas y tipologías, dado que pese a caracterizarse por sus elevadas precipitaciones, abundantes lagos y ríos, contradictoriamente diversas localidades sufren de escasez de agua, siendo abastecidas de agua potable mediante camiones aljibes desde el año 1996, situación que continua en aumento. Al mismo tiempo, el área concentra la mayor superficie de plantaciones forestales exóticas de la región (CONAF, 2016), las cuales son identificadas por actores de la sociedad civil y el Estado local como un elemento que impacta negativamente la disponibilidad del recurso hídrico en la zona (Oppliger, 2016).

Basadas en la importancia que tienen los monocultivos forestales de especies exóticas en la disminución de los recursos hídricos disponibles en un territorio (Buchs, 2010), argumentamos que la invisibilizacion, por parte del Estado central y las empresas forestales, de los consumos de agua de las plantaciones forestales, entre otros aspectos, forman parte importante de los orígenes antrópicos de la escasez de agua en el territorio. Para comprobar este hecho, y revelar la pluralidad de causas y manifestaciones de la escasez de agua, presentamos los resultados de una investigación realizada en la sección baja de la cuenca del río Bueno desde el año 2011. 
La investigación se basa en una revisión de documentos e informes técnicos del Estado, de sistemas de agua potable rural, organizaciones de regantes, bonificaciones forestales del D.L.701, registros de entrega de agua potable por camiones aljibe, entre otros. Asimismo, se realizaron jornadas de terreno con observaciones de campo y entrevistas con actores clave en los años 2011, 2012 y 2016, junto a la participación pasiva en reuniones del Subcomité de Asuntos Hídricos de la provincia del Ranco en el 2016. La información obtenida fue estructurada mediante el software ATLAS.ti y analizada de forma cualitativa mediante el enfoque de los estudios críticos del discurso (ECD) (Pardo, 2012). Así, identificamos tres grupos de actores principales vinculados a la gestión del agua, su escasez y el recurso forestal en el territorio: el Estado de Chile en sus diferentes niveles organizacionales; la Sociedad Civil representada por comités de agua potable rural (APR), pequeños agricultores y habitantes de localidades rurales abastecidos por camiones aljibes; y grupos de privados, representados por las principales empresas forestales del área de estudio: Arauco SA., Masisa SA. y AnChile Ltda, y la empresa Sanitaria Essal SA.

Los resultados apoyan el argumento de que la escasez de agua en la zona no responde únicamente a causas físicas, como la disminución de precipitaciones, sino también a causas antrópicas. En primer lugar, el hecho de que no todos los actores del territorio sufran de escasez de agua, demuestra la existencia de factores sociales que afectan la disponibilidad de las fuentes hídricas. En segundo lugar, el esquema de tipologías de escasez de agua permitió identificar una amplia gama de factores sociales que originan la escasez, así como la descoordinación institucional del agua y su escasez. En base a esto, argumentamos que el problema de la escasez de agua en el país no se podrá solucionar mientras se insista en su naturalización y sin reconocer sus causas sociales y políticas, además de las naturales o físicas, que puedan llevar a las necesarias reformas estructurales en la gestión del agua y su escasez, a nivel nacional, regional, y local.

A continuación, presentamos el marco teórico que sustenta el presente trabajo, enfocado en la ecología política del agua y las tipologías de escasez de agua. Después analizamos la gestión institucional del agua y su escasez en Chile, y presentamos el caso de estudio. La sección de resultados contiene los principales hallazgos de la investigación que sostienen nuestro argumento; concluimos el artículo discutiendo los resultados, a la luz de la institucionalidad chilena y las mejoras necesarias en torno a la gestión del agua y su escasez.

\section{Ecología política del agua}

La ecología política pone su énfasis en analizar las múltiples relaciones existentes entre la naturaleza y la sociedad (Prieto, 2015), desde una perspectiva donde la naturaleza constituye el resultado de una construcción socio-natural, que captura y encarna procesos que son simultáneamente físicos y sociales, y que hacen de ella una cosa "híbrida" (Swyngedouw, 2009).

En su vínculo con el agua, la ecología política enfatiza las relaciones de poder que subyacen en el recurso, entendiendo al agua más allá de la entidad material dada por la fórmula de $\mathrm{H} 2 \mathrm{O}$ (Linton y Budds, 2014). En concordancia, el enfoque invita a pensar el agua como un elemento y un proceso; donde además de incorporar en su análisis a la materialidad del agua, invita a analizar cómo esta materialidad se vincula con las infraestructuras hídricas, las políticas, así como los procesos económicos, sociales y culturales envueltos en torno a la producción de esa "agua" (Linton y Budds, 2014) que interactúa a través de relaciones de poder y escalas geográficas, gene- 
ralmente invisibilizadas (Swyngedouw, 2013). De esta manera, la ecología política del agua asiste deliberadamente a la naturaleza social y política del agua, que a diferencia del análisis del ciclo hidrológico - que tiene el efecto de separar al agua de su contexto social - pone énfasis en analizar sus prácticas y relaciones sociales (Linton y Budds, 2014). Para Swyngedouw (2009), las relaciones sociales por las cuales se produce el agua, se movilizan a través de lo invisible y a través de procesos de "inscripción" donde se entrelazan lo global y lo local (Swyngedouw y Heynen, 2003), a lo que se suman la diversidad de escenarios culturales, sociales y político-económicos de la geografía, junto a su movilización histórica (Swyngedouw, 2014). Con ello, el enfoque apela a las características de transformación de la materia, para argumentar que estos cambios, no sólo transforman a la materialidad del agua, sino que a su vez transforman y cambian los procesos sociales, los que a su vez modifican y vuelven a transformar a la materia en este proceso de inscripción, donde las nuevas formas de organización social se forjan a través de la producción de nuevos entornos hidrosociales (Swyngedouw, 2014), que son el resultado de un proceso de producción histórico-geográfico (Swyngedouw y Heynen, 2003). Bajo este contexto, desde la ecología política del agua, reconocemos que la escasez de agua constituye un fenómeno de naturaleza "hibrida", que responde a causas tanto naturales como humanas (Prieto, 2015). A continuación, indagamos en la literatura pertinente para facilitar la comprensión de la construcción de este fenómeno y sus distintas causas y manifestaciones físicas y sociales, sintetizadas en un esquema de tipologías de escasez de agua.

\section{Tipologías de escasez de agua}

El concepto de escasez es ambiguo y difícil de comprender debido a las diferentes dimensiones que presenta (Harvey, 1985). De esta manera, diferentes disciplinas tales como la geografía (Budds, 2012; Kaika, 2003) estudios del desarrollo (Mehta, 2007), hidrología (Huber et al., 2008), ciencias forestales (Lara et al., 2009; Iroume et al., 2010) o agronómicas (Rijsberman, 2006), entre otras, han abordado el concepto de la escasez de agua desde distintos ángulos y atribuido a diferentes orígenes, los cuales, hemos sistematizado para facilitar su comprensión, en el siguiente esquema de tipologías de escasez de agua.

En términos generales se identifican dos grandes vertientes que definen la escasez de agua: una "escasez física" o "sequía" (Esparza, 2014) que respondería a causas naturales que la originan; y otra "escasez social" o "socialmente construida" (Cooley et al., 2014).

En cuanto a la "escasez física", Esparza (2014) señala que ésta puede ser subdividida en tres categorías. La primera de ellas, corresponde a la "sequía meteorológica" (Marcos, 2001), que dependerá de la existencia de un registro climático amplio de precipitaciones. Segundo, una "sequía del tipo agrícola", entendida como la inexistencia de humedad suficiente en el suelo (Esquivel, 2002), y un tercer tipo de "sequía hidrológica", entendida como el descenso paulatino del nivel de las aguas de los ríos, lagos, embalses o pozos (Ashton y Neal, 2003). Otros autores reconocen una cuarta categoría, producto de causas naturales de contaminación de las aguas a través de su composición química (Máñez et al., 2012). 
Figura N01. Tipologías de escasez de agua.

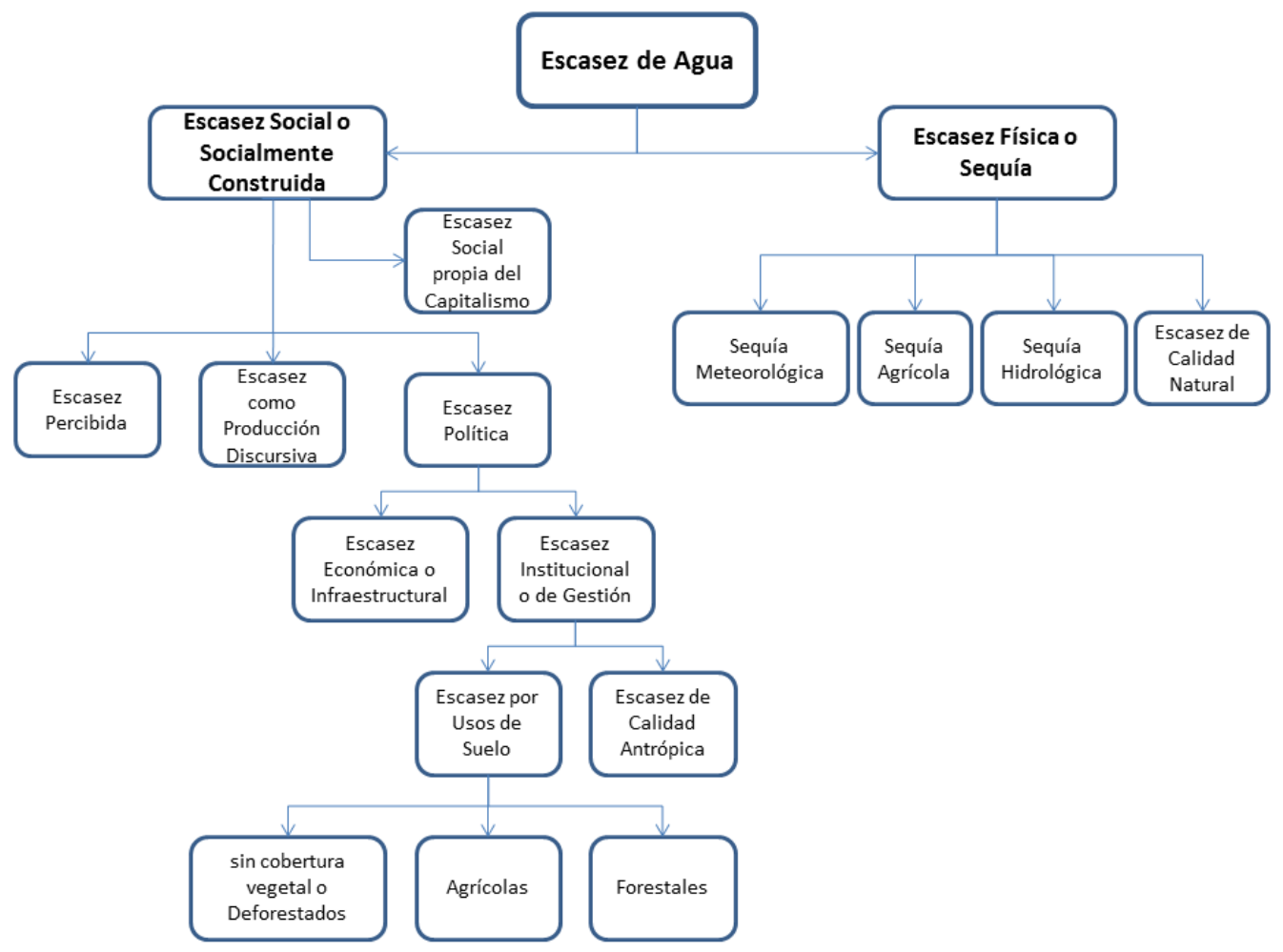

Fuente: elaboración propia. Oppliger, 2016.

Por otra parte, la "escasez social" o "socialmente construida" (Buchs, 2010), se compone por una amplia variedad de categorías. En un nivel de abstracción analítico mayor, autores como Harvey (1985), se refieren al término de "escasez social" como un concepto "propio del capitalismo" donde fenómenos como la apropiación, explotación y privación son consecuencias necesarias para el buen funcionamiento del sistema de mercado, por lo que éste, le sería un término intrínseco. Otros autores reconocen la "escasez percibida", entendida como "la forma en que la escasez es sentida por la gente" (Máñez et al., 2012: 15), la que resulta importante, puesto que proporciona la base sobre la cual la gente toma sus decisiones para actuar y nos aporta indicios sobre "los significados culturales del agua que no son capturados en los debates políticos" (Mehta, 2007: 661). En otra línea, autores como Kaika (2003); Mehta (2007) y Swyngedouw (2009), entre otros, hacen alusión al término de "producción discursiva de la escasez de agua" (Swyngedouw et al., 2002: 132), la cual hace referencia a las especulaciones políticas en torno a las discusiones de la gestión del agua, cuyos discursos a menudo son utilizados con intereses particulares como "arreglos institucionales formales que tienden a reforzar la posición de las elites tradicionales" (Mehta, 2007: 659), lo que requiere de un empleo cuidadoso del término de escasez, cuestionarse e identificar quién se pudiera beneficiar de la misma. 
Finalmente, como una tercera subtipología de escasez social se encuentra la "escasez política" (Buchs, 2010) que, compuesta por variadas subcategorías, es referida como todos los aspectos sociopolíticos y normativos, con implicancias económicas, infraestructurales, tecnológicas, culturales, de usos de suelo, entre otras, que una sociedad desarrolla en su relación con el agua. De esta forma, "en términos políticos, el agua fluye cada vez más de acuerdo con los flujos del capital" (Linton y Budds, 2014: 172), donde se reconoce que el agua se moviliza de manera intencionada hacia ciertos sitios y no a otros en el territorio, brindando la posibilidad de que algunos grupos de actores puedan desarrollar o no su actividad productiva, con la consecuente obtención de bonanzas económicas. Por este motivo, bajo ella encontramos en primer lugar, la "escasez económica" o "infraestructural" (Mehta, 2007; PNUD, 2006), enfocada en el análisis de las relaciones entre el poder económico y político, a través de las cuales se obtiene el acceso, distribución y control del agua mediante la construcción de infraestructuras (Swyngedouw, 2009); otros autores como (Feitelson y Chenoweth, 2002) se refieren a ella como "pobreza de agua", cuando el coste del saneamiento no es sostenible por toda la población de una región o nación. En segundo lugar, se puede identificar "la escasez institucional" o "de gestión" (Budds, 2009; 2012), que centra su foco de análisis en cómo las formas de gestión de las aguas son condicionadas por la vida política, institucional y administrativa, y ya sea que éste se base en la tradición o hábitos recientes de consumo del agua (Wolfe y Brooks, 2003). Desde la "escasez de gestión", la literatura reconoce la existencia de una escasez de agua derivada de los "usos de la tierra" (Mehta, 2001) y como factores gatillantes, por un lado la "deforestación de los suelos" (Metha, 2007), y por otros, malas prácticas en torno a los "usos de suelo agrícolas" (Máñez et al., 2012) y "usos de suelo forestales" (Huber et al., 2008; Little et al., 2009). Finalmente, desde la "escasez de gestión", la literatura reconoce la existencia de una "escasez de calidad de origen social o antrópico" (Cooley et al., 2014), que se produce derivada de prácticas inadecuadas de gestión, que promueven la contaminación antropogénica sobre el agua (Máñez et al., 2012), lo que reduce significativamente su disponibilidad para el consumo humano, haciéndola más escasa (Esparza, 2014).

De esta forma el problema mundial de la escasez de agua, se vincula con las relaciones sociales que determinan quiénes, cómo y por qué utilizan el agua (Kaika, 2003) condicionando su distribución y la construcción de su escasez. Por lo que en este artículo, haciendo un reconocimiento de la naturaleza hibrida del agua, analizaremos desde la perspectiva de la "construcción social de la escasez de agua" (Buchs, 2010; Swyngedouw, 2013) cómo se gestiona el agua y su escasez en Chile.

\section{Gestión institucional de la escasez de agua}

Las dos principales características de la gestión hídrica en Chile son la comodificación del agua (Budds, 2009), y una fuerte centralización en la toma de decisiones (Mascareño, 2010). A continuación, analizaremos de qué manera estos dos aspectos inciden en la imposición de una visión tecnócrata en los procesos de toma de decisiones acerca de la gestión del agua y su escasez a lo largo del país, naturalizando al mismo tiempo las causas de la última.

La gestión del agua en Chile se identifica con los mercados de aguas (Bauer, 2004), un sistema de asignación de derechos de agua que es tecnocrático y eficiente; por ende, es supuestamente 
políticamente neutral (Prieto, 2015), y se deriva del Código Chileno del Aguas, creado e implementado durante la dictadura de Pinochet (Budds, 2013). Las principales implicaciones del Código fueron la separación de los derechos del agua con los de la tierra, la asignación gratuita y perpetua de los primeros a los solicitantes, y la falta de priorización entre los distintos usos de agua (Donoso, 1999). Estas condiciones básicas permitieron la compra y venta de agua como cualquier otro producto del mercado, a través de transacciones de derechos de aprovechamiento de aguas (Budds, 2009), dejando a los mercados la labor de asignación "natural" de aguas en la actividad económicamente más rentable (Budds, 2009). Varios autores han demostrado que estas reformas neoliberales han sido una condición necesaria para favorecer la economía de exportación, impulsando especialmente la agroindustria, el sector forestal y la minería (Palomino-Schalscha et al. 2016).

Estas condiciones estructurales han apuntado a restringir las facultades del Estado en materia de gestión (Frene y Núñez, 2010). Asimismo, la descentralización que acompaño los procesos de privatización y comodificación del agua (Larson y Soto, 2008) no transfirió poder a los gobiernos regionales y locales, limitándolos a la ejecución de decisiones y políticas elaboradas en Santiago (Barton, 2013). Sin embargo, la escasez de agua en Chile ha sido abordada principalmente desde los Municipios y Gobernaciones que financiaban y continúan financiando, la compra de camiones aljibes para el abastecimiento de agua potable de localidades con escasez. Los esfuerzos estatales a nivel central para superar la escasez de agua son, por lo tanto, recientes y cuentan con medidas como una Comisión permanente sobre el agua, la desertificación y la sequía en la Cámara de Diputados en 2012 (Szigeti, 2013), la asignación de un Delegado Presidencial para Recursos Hídricos en 2014 (Bauer, 2015), la Política Nacional de Recursos Hídricos y el Plan Nacional de Adaptación al Cambio Climático, entre otras series de medidas infraestructurales ante la sequía, tales como el Plan Nacional para la Sequía, a financiar con 150 millones de dólares.

Por otra parte, como medidas de emergencia ante la escasez de agua, el Estado chileno desde el nivel central, está facultado, por un lado, para declarar zonas de escasez hídrica (Código de Aguas, 1981). Los criterios para emitir un decreto de escasez, se basan en condiciones hidro-meteorológicas de precipitaciones, caudales de ríos, volúmenes de embalses y condiciones de acuíferos (Decreto N¹674 DGA, 2012). Por el otro lado, el Ministerio de Agricultura, frente a eventos climáticos extremos, como sequias y catástrofes naturales, puede declarar una emergencia agrícola, con miras de proteger la producción (Núñez et al. 2013), la que también, se desarrolla en base a criterios técnicos hidro-meteorológicos (FAO/Ministerio de Agricultura 2011). Sin embargo, la proclamación de decretos de escasez y de emergencia agrícola desde el nivel central, no sólo refuerzan la tesis de la toma de decisiones centralizada y limita a la gestión de la escasez de agua a una meramente física y tecnócrata; sino que también, promueven la invisibilización de las realidades, geográficas, económicas, sociales y culturales de los diversos territorios locales.

Esta naturalización de la escasez de agua en sus aproximaciones metodológicas, y definición a nivel conceptual, así como la falta de reconocimiento de su naturaleza híbrida como un fenómeno socionatural (Swyngedouw, 2009) tiene serias implicaciones. En consecuencia, la invisibilización de algunas de las causas fundamentales de la escasez puede conducir a soluciones inadecuadas (Mehta, 2001), cómo las encontradas en la cuenca baja del Río Bueno. 


\section{Cuenca del río Bueno: territorio lluvioso con escasez de agua}

La sección baja de la cuenca del rio Bueno se ubica en la zona oeste de la ciudad de La Unión, capital de la provincia del Ranco, en la región de Los Ríos en Chile, cuya capital es Valdivia. El área se compone de un total de 44 localidades rurales, conformadas por un total de 3.077 habitantes, y con un 9,2"\% de población perteneciente a la etnia Mapuche (CENSO, 2002).

El área se caracteriza por el desarrollo de la actividad forestal, principalmente del tipo industrial, y en menor medida por la producción agrícola de hortalizas en pequeñas chacras a las orillas del río Bueno (PLADECO, 2011). La actividad forestal del área se enmarca en el actual desarrollo monoforestal de especies exóticas localizadas en el centro-sur del país (Little et al., 2009), incentivados por las reformas político-económicas implementadas en Chile durante la década del 70 (Frene y Núnez, 2010). El área de estudio se caracteriza por ser la zona de mayor superficie de plantaciones forestales de especies exóticas en la Región de Los Ríos (CONAF, 2016). Su producción mayoritariamente es exportada (72\%) (INFOR, 2015) y entre las principales especies forestales destacan el Eucalyptus nitens y Pinus radiata (CONAF, 2016). Los indicadores socioeconómicos revelan que la pobreza comunal es superior al promedio nacional (PLADECO, 2011), lo que también se ve reflejado en la paúpera infraestructura de agua potable rural (APR) del área, con sólo cuatro APR operativos y cuatro en fase de diseño al 2016 (DOH, 2016).

La región posee un clima templado lluvioso con influencia mediterránea, y es conocida a nivel nacional por sus elevadas precipitaciones (DGA, 2016), con un promedio anual entre los 1.000 y $2.000 \mathrm{~mm}$ anuales; $y$ cuya tendencia de precipitaciones ha registrado disminuciones particularmente durante el otoño, y en febrero y marzo, con concentraciones de la precipitación en invierno (González y Muñoz, 2013).

A pesar de las abundantes precipitaciones, en el año 1996 empieza a circular el primer camión aljibe en la zona para brindar agua potable a la población rural más afectada por la escasez de agua, que se manifestaba con la disminución de caudales en esteros y pozos de agua (Oppliger, 2011). El decrecimiento de las aguas ha sido paulatino con el transcurso de los años, manifestándose entre los meses de octubre a abril y agudizándose en época estival, especialmente entre enero y marzo, donde es posible observar el fenómeno del secamiento de esteros y pozos de agua (Oppliger, 2016).

A pesar de la circulación de camiones aljibe desde el año 1996, la Dirección General de Aguas (DGA) no ha emanado Decretos de Escasez de Agua para la comuna de la Unión o región de Los Ríos. El Ministerio de Agricultura, en cambio, ha emitido declaraciones de Emergencia Agrícola por Déficit Hídrico, lo que indica períodos de sequía del tipo agrícola (Esquível, 2002).

Asimismo, las plantaciones forestales de especies exóticas consumen agua e impactan la disponibilidad hídrica (Huber et al. 2008; Little et al. 2009). El sector forestal no debe adquirir derechos de aprovechamiento de aguas para el desarrollo de su actividad productiva, y ha sido asociado frecuentemente con la propagación de la escasez de agua (Torres-Salinas et al., 2016). C, su expansión ha provocado tensiones entre organismos gubernamentales, empresas (multi) 
nacionales, la población local y grupos no-tradicionales en zonas con gran presencia forestal (INDH, 2015).

\section{El origen híbrido de la escasez de agua en la cuenca del río Bueno}

A continuación, se presentan los resultados de nuestra investigación en la cuenca baja del río Bueno; estos están distribuidos en tres apartados, y responden a equivalentes preguntas sobre: cuáles son los actores que están afectados por la escasez hídrica; a qué causas atribuyen dicha escasez los mismos actores; y finalmente, cuáles tipos de escasez se manifiestan en el territorio bajo estudio, según la clasificación de nuestro marco teórico.

\section{Escasez hídrica y principales actores asociados a la gestión y uso del agua}

Para determinar quiénes de los actores en la zona de estudio sufren de escasez agua se trianguló información proveniente de cuatro fuentes: registros oficiales de distribución de agua por camiones aljibe del Municipio de La Unión; análisis de documentos oficiales del Estado a nivel nacional; entrevistas con representantes del Estado a nivel regional y local, de las empresas forestales presentes en el área de estudio, así como con la sociedad civil; y observaciones directas de campo.

El análisis de los principales actores frente a la escasez de agua revela en primer lugar que el fenómeno de escasez de agua no los afecta de manera homogénea (figura 2). En segundo lugar, los resultados indican que el único actor directamente afectado por la escasez es la sociedad civil. Según los relatos de los pobladores viviendo en la sección baja de la cuenca del río Bueno, la escasez tiene sus inicios a principios de los años 90 y se ha manifestado en la disminución y secado en verano de esteros y pozos de agua. Asimismo, el número de camiones aljibe ha aumentado de 1 a 3, abasteciendo en el año 2016 a 15 de las 32 localidades rurales con escasez de agua (figura 3). Asimismo, dos de los cuatro sistemas de APR operativos sufren problemas de escasez de agua, debiendo ser complementadas por camiones aljibes. Mientras que el APR de Mashue, pese a no sufrir de escasez de agua en el 2016 (en el 2012 si sufría de escasez), se ve indirectamente afectado por la escasez hídrica, dado a que invierte tiempo y recursos económicos en el manejo de sus microcuencas hidrográficas, para resguardar el recurso hídrico y superar la escasez de agua.

El Estado a nivel local sufre de manera indirecta la escasez de agua porque debe invertir tiempo y recursos económicos de manera constante para brindar soluciones a la escasez de agua que sufre la sociedad civil. Sus primeras acciones datan del año 1996, año en que empieza a circular el primer camión aljibe en la comuna. A 20 años del primer camión aljibe el Municipio ha aumentado el número de camiones aljibe a tres, que reparten agua de lunes a viernes, durante todo el año. Las labores a nivel local son apoyadas por la Gobernación Provincial de Ranco y la Oficina Nacional de Emergencia (ONEMI), mediante el arriendo de camiones aljibe adicionales durante el verano. El hecho de que actualmente la Municipalidad realiza gestiones para comprar un cuarto camión aljibe demuestra que el problema de la escasez se está agravando y que las medidas 
tomadas hasta la fecha son insuficientes. De esto también da cuenta el establecimiento del Subcomité de Asuntos Hídricos de la Provincia de Ranco en el año 2015 cuyo objetivo consiste en brindar solución a la escasez de agua de la provincia.

Figura No2. Actores asociados a la gestión y el uso de agua en el caso de estudio, y su vinculación con la escasez hídrica.

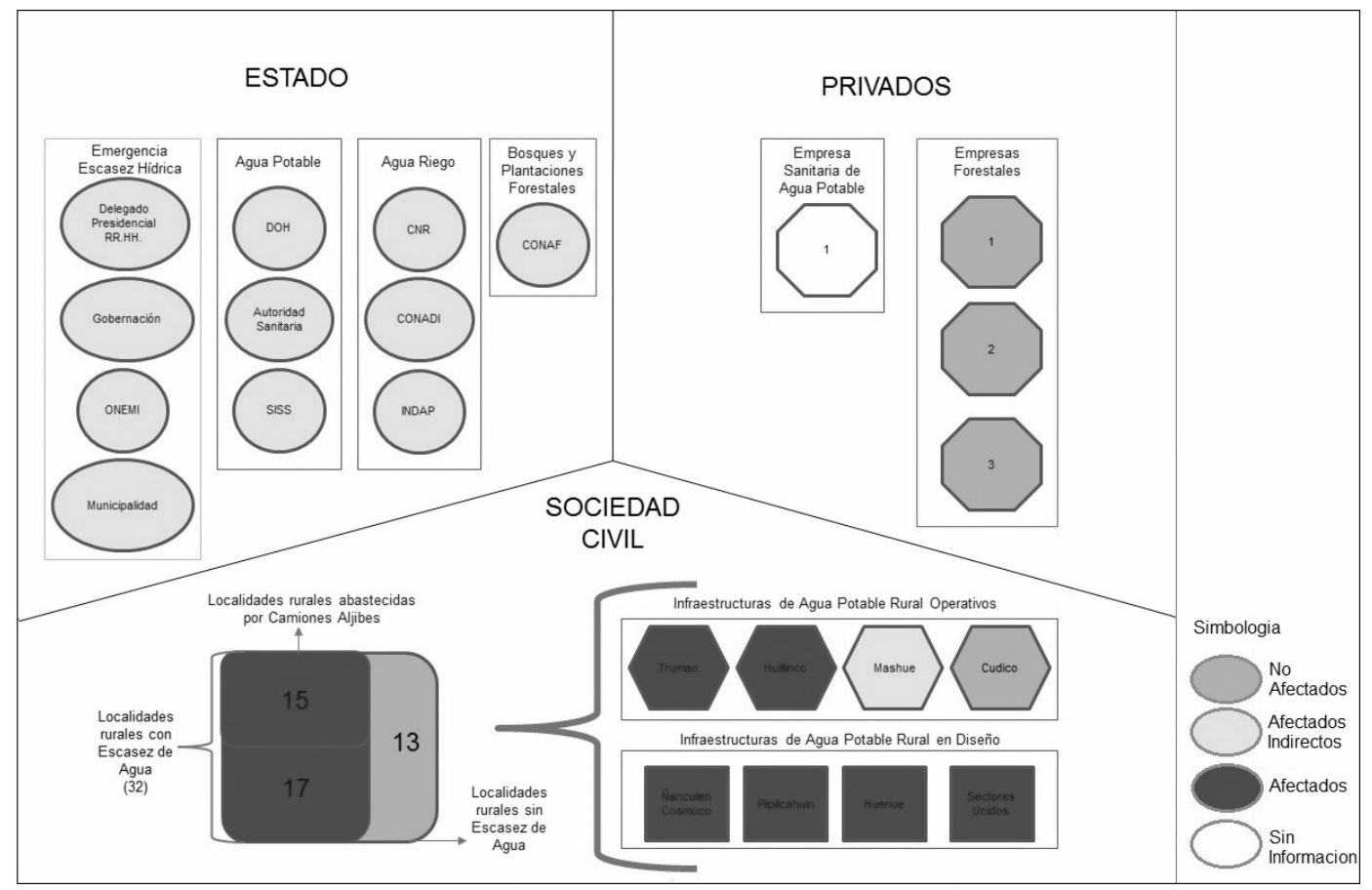

Fuente: Elaboración propia. Oppliger, $2016^{4}$.

Finalmente, las tres empresas forestales del área de estudio, declaran no sufrir escasez de agua. Sin embargo, reconocen recientemente la existencia de escasez de agua en la zona y datan su inicio en el año 2010. Con respecto a la empresa sanitaria regional, ESSAL (Empresa de Servicios Sanitarios de los Lagos), no se realizaron entrevistas con esta empresa, por lo que no se pudo indagar en su situación frente a la escasez hídrica.

Acrónimos de la figura 2. RR.HH: Recursos Hídricos; ONEMI: Oficina Nacional de Emergencia del Ministerio del Interior; DOH: Dirección de Obras Hidráulicas; SISS: Superintendencia de Servicios Sanitarios; CNR: Comisión Nacional de Riego; CONADI: Corporación Nacional de Desarrollo Indígena; INDAP: Instituto de Desarrollo Agropecuario; CONAF: Corporación Nacional Forestal. 
Figura N³. Localidades rurales del área de estudio con escasez de agua en los años 2011 y 2016. Sección baja de la cuenca del rio Bueno.
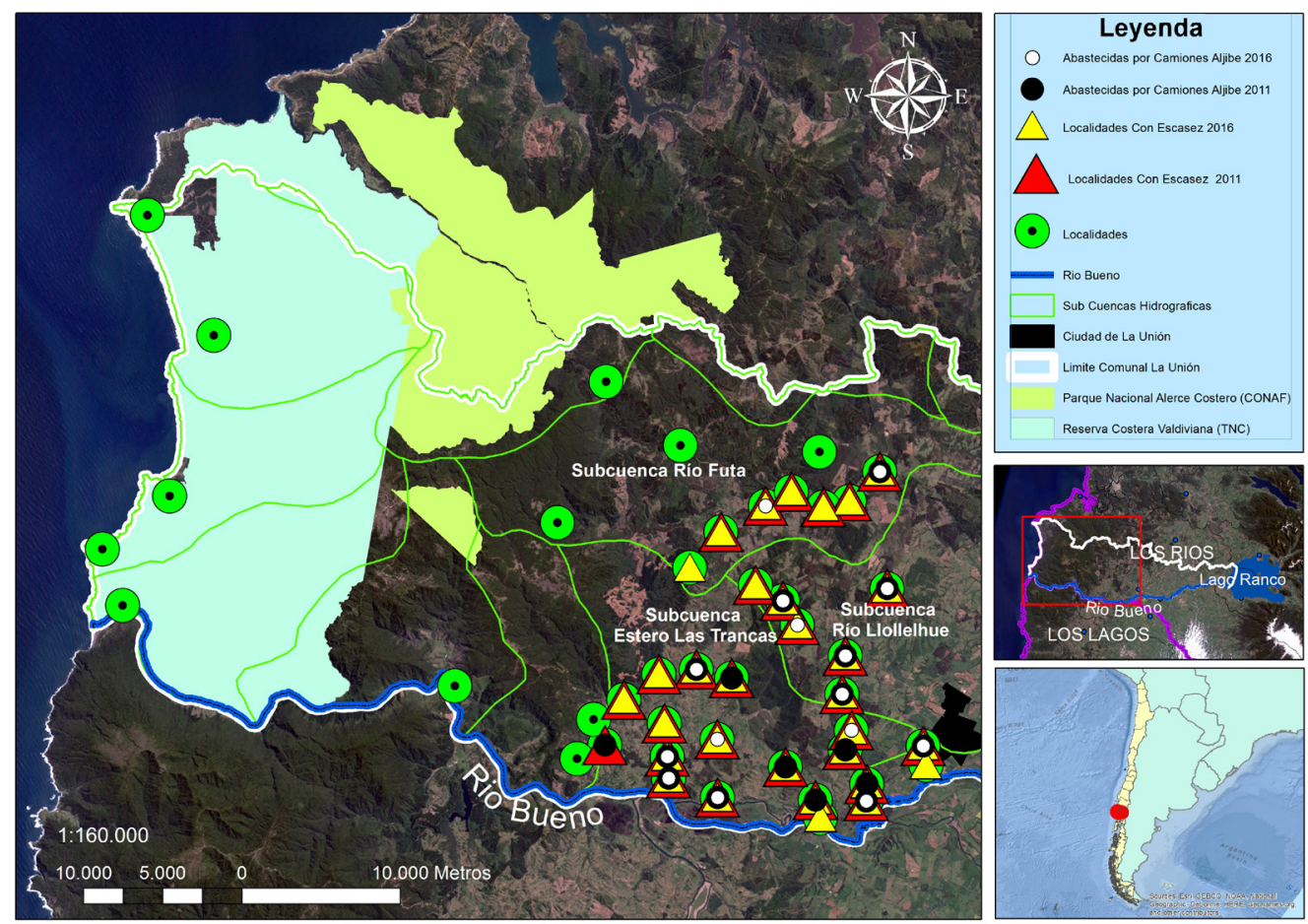

Fuente: Elaboración propia. Oppliger, 2016.

\section{Causas atribuidas a la escasez de agua}

El Estado, la sociedad civil y las empresas forestales no sólo determinan diferentes fechas de inicio de la escasez de agua, pero los resultados revelan que coexiste una gran variedad de formas de comprensión y explicaciones de sus orígenes. Los actores estatales, privados y la sociedad civil atribuyen la escasez de agua tanto a causas físicas como sociales en la cuenca baja del río Bueno, por lo que se evidencia el reconocimiento de la naturaleza híbrida del fenómeno. La sociedad civil responsabiliza en primer lugar a las plantaciones forestales de especies exóticas, y en segundo lugar, al cambio climático. Otras causas mencionadas por representantes de la sociedad civil comprenden la contaminación antrópica de las aguas, la deforestación del bosque nativo y eventos naturales eventuales (como terremotos), así como también, malas prácticas históricas en torno a los usos de suelo agrícolas y forestales, y las lógicas de explotación y uso de los recursos naturales del modelo económico neoliberal (Oppliger, 2011; 2012; 2016).

A partir del análisis de los datos reconocemos un giro en las causas a las que las organizaciones estatales atribuyen la escasez de agua. Mientras que en el año 2011 tanto a nivel nacional como local los orígenes identificados por parte del Estado eran netamente físicos, tales como el cambio climático y la disminución de precipitaciones (Oppliger, 2011; 2012), en el año 2016 el 
Municipio y miembros del Subcomité de Asuntos Hídricos reconocen la existencia de orígenes sociales. Los funcionarios de corte técnico de estas instituciones responsabilizan como principal factor que agrava la escasez de agua en el territorio los usos de suelo forestales de especies exóticas. Asimismo, reconocen la falta de un ordenamiento territorial rural y deficiencias en la fiscalización y coordinación entre los servicios Estatales que, por ejemplo, no permiten proteger las fuentes de agua ante eventos de contaminación antrópica generados por empresas sanitarias y lecherías entre otros, como factores que han incrementado la escasez de agua en el territorio.

También las empresas forestales presentan un giro en torno a las causas a las que le atribuyen la escasez del agua. En el marco de reuniones sostenidas en el año 2012 determinaban como orígenes del fenómeno el cambio climático y la disminución de precipitaciones. En el año 2016, en cambio, incorporan nuevos argumentos a sus discursos que apuntan a los consumos de agua por usos de suelos agrícolas, la dinámica indígena, el aumento de la población y la explotación de la tierra, así como el reconocimiento parcial de las plantaciones de especies exóticas, como los causantes de la escasez de agua en la zona. Este giro es también una respuesta a los discursos de la sociedad civil y agentes estatales quienes responsabilizan a las plantaciones de especies exóticas de la escasez de agua, lo que es un giro importante en torno a su rol frente a la escasez hídrica en la zona.

\section{Tipologías de escasez de agua}

El presente trabajo ha evidenciado que el fenómeno de la escasez de agua no afecta de manera homogénea a los diferentes actores en el área de estudio; lo que revela la existencia de orígenes de la escasez de agua que van más allá de un tipo de escasez meramente física, explicitando la existencia de orígenes sociales, lo que demuestra la naturaleza hibrida de la escasez de agua (Swyngedouw, 2009).

Asimismo, hemos identificado en el área de estudio diferentes tipologías de escasez de agua que sostienen nuestro argumento de la hibridez del fenómeno. En primer lugar, evidenciamos la existencia de "pobreza de agua" en el caso de la APR de Cudico, cuya cobertura de acceso al agua potable no es universal para la comunidad, continuando dos familias de Cudico abasteciéndose de agua potable mediante el camión aljibe municipal, dado que estas no tuvieron los recursos económicos para pagar e incorporarse al sistema de APR.

Por otra parte, el hecho de que de las cuatro infraestructuras de APR operativas en el área de estudio, dos sufran de escasez de agua, devela la existencia de una segunda tipología de escasez que corresponde a "problemas institucionales y de gestión" a la hora de abordar temas integrales del agua. Principalmente los hechos identificados, tienen que ver con las decisiones del Estado y la inversión en infraestructuras asociadas; donde la falta de coordinación entre las distintas instituciones estatales de los niveles regional y local y entre cada nivel, causa la pérdida de recursos económicos y la generación de nuevas externalidades negativas que recaen en las APR o los habitantes rurales, algunos de los cuales deben resolver la escasez por sus propios medios, desplazándose para la recolección de agua.

Otros ejemplos que ilustran la "escasez institucional de agua", debido a formas institucionales y administrativas inadecuadas de gestión, son los siguientes: "Pozo profundo del APR de Pilpilca- 
huin". Inaugurado en el año 2010, buscaba dar solución a la escasez de agua para consumo humano en esta localidad rodeada de plantaciones forestales. Se invirtieron 300 millones de pesos en su diseño y construcción. Los recursos se perdieron, ya que con 120 metros de profundidad el pozo nunca encontró agua y hoy se levanta como un elefante blanco en la localidad de Pilpilcahuin. Hoy, un nuevo proyecto de APR se ha diseñado y esperan la fase de construcción. Esta nuevo APR captara aguas superficiales desde subcuencas con bosque nativo distantes de la localidad de Pilpilcahuin, lo que ha encarecido y retrasado el inicio de su construcción. "Cortes de planzas (cañerías) del APR de Huillinco". En el 2015 la Dirección de Vialidad del Ministerio de Obras Públicas (MOP) inicia las obras del proyecto de mejoramiento de la Ruta T-80, desde Trumao a Las Trancas con una inversión de 3.270.283.412 millones de pesos. Por falta de coordinación e información entre servicios, las obras de la empresa consultora contratada por el MOP han cortado constantemente, y en distintos puntos las planzas (cañerías) de la red de agua potable del APR de Huillinco instaladas por la DGA en el 2009. Esto ha ocasionado escasez de agua a la APR de Huillinco por fugas de agua constantes y grandes inconvenientes en la triplicación de costos por consumo energético de sus bombas de agua. Al 30 de marzo de 2016, ni Vialidad, ni la Dirección de Obras Hidráulicas ( $\mathrm{DOH})$, habían brindado una solución definitiva o compensación económica por los daños ocasionados, cuyos costos han debido ser asumidos íntegramente por el APR de Huillinco. Si bien, estos casos revelan también falencias infraestructurales, se requiere de un mayor análisis para corroborar el vínculo con la tipología de escasez de agua infraestructural en la zona.

Otra tipología de escasez de agua identificada corresponde a la "escasez de agua por usos de suelo forestales". Sólo entre los años 2000 y 2014 el Estado ha promovido en el área de estudio la reforestación de 5.032 ha de especies exóticas con subvenciones otorgadas a grandes y pequeños propietarios forestales mediante el D.L.701 de CONAF (CONAF, 2016 b). Las tres empresas forestales de este estudio cuentan con 47.364 ha de plantaciones exóticas, presentando la mayor superficie de ocupación espacial en el área de estudio. Estas "bio-infraestructuras" ${ }^{5}$ consumen agua de forma constante abasteciéndose de agua de manera autónoma a través de su desarrollo radicular captando aguas Iluvias, aguas superficiales o subterráneas. Sin embargo, las plantaciones forestales de especies exóticas poseen una ventaja sustancial en el acceso al agua, ya que no necesitan infraestructuras hídricas para abastecerse de agua, ni adquirir derechos de aprovechamiento de agua en comparación con las actividades productivas agrícolas o de consumo humano. Por lo tanto, los consumos constantes de agua por parte de las plantaciones forestales, al no ser cuantificados, son invisibilizados del balance hidrológico de las cuencas hidrográficas.

Finalmente, otro ejemplo, constituyen los eventos de contaminación eventuales en el río Bueno provocados, por la empresa sanitaria ESSAL SA y fundos lecheros, entre otros (Mesa del Agua, 2016), lo que impide a los APR de Trumao y Huillinco captar agua de manera constante, ocasionando la construcción de una cuarta tipología de "escasez de calidad antrópica". Por lo tanto, develamos que en la zona de estudio no sólo se presenta una escasez física, sino diferentes orígenes sociales que se derivan de la tipología de "escasez política" que se centra en aspectos de influencia sociopolítica y normativa como causantes de la escasez hídrica.

Las bio-infraestructuras, corresponden a aquellas infraestructuras que diseñadas, construidas y organizadas espacialmente por la razón y actividad humana, se componen principalmente por un conjunto de elementos orgánicos (y en ocasiones inorgánicos); tales como vegetales o árboles, pudiendo corresponder a cultivos agrícolas, plantaciones forestales, áreas verdes, entre otros. 


\section{Conclusiones}

El presente estudio demuestra el complejo escenario de escasez hídrica en las zonas rurales de Chile, reflejando las complejas dinámicas entre los actores locales, y su desarticulación con los representantes estatales a nivel regional y nacional. Este contexto se refleja en las inadecuadas soluciones que se ofrecen al territorio analizado; la naturalización de las causas de la escasez hídrica a nivel central tiene como resultado la implementación de soluciones infraestructurales y técnicas que no logran superar la escasez experimentada por los habitantes. La distribución de agua con camiones aljibe a localidades dispersas que no cumplen los requisitos para formar APRs, por un lado, es una medida de emergencia - insostenible a largo plazo, siendo costosa para las autoridades locales, ymediano y largo plazo para satisfacer la demanda de agua potable poco aceptada por la gente. Por otro lado, medidas de mediano y largo plazo, tales como la profundización de pozos y la creación de nuevas APRs, tampoco han mejorado la situación, develando probablemente el impacto de la expansión forestal en la disponibilidad de agua e indicando a una escasez hídrica por usos de suelos.

Sin embargo, la invisibilización del consumo de agua de las plantaciones forestales le permite al Estado priorizar su desarrollo económico. Estas bio-infraestructuras no forman parte del sistema de asignación de derechos de aprovechamiento de aguas, quedando no sólo sus consumos fuera de los balances hídricos de las cuencas hidrográficas, sino permitiéndoles también hacer uso del recurso sin costo asociado. En este sentido, la no cuantificación -con precisión generalizable- de los consumos hídricos forestales, constituye el mecanismo que construye la invisibilización de los consumos de agua de las plantaciones forestales y las desvincula a priori de potenciales responsabilidades en torno al incremento de la escasez de agua.

Por lo tanto, la naturalización de la escasez de agua favorece tanto al sector forestal como a la agricultura, minimizando los incentivos para reducir la demanda hídrica. Las herramientas normativas del Estado a nivel central frente al reconocimiento de la existencia de escasez hídrica sustentan este argumento. La declaración de emergencia agrícola se basa en la disminución de precipitaciones y de agua en el suelo, y permite agilizar medidas y recursos para proteger las actividades agrícolas. Por lo tanto, esta gestión se centra en dar respuestas técnicas a la escasez física y prioriza el uso del agua para fines agrícolas.

Concluyendo, la naturalización discursiva del fenómeno de la escasez de agua ha permitido al Estado evitar hacerse cargo de sus causas antrópicas, de orígenes políticos y económicos, permitiendo al mismo tiempo mantener la hegemonía política, social y cultural en el país, a través del control de sus recursos hídricos. La propuesta de soluciones orientadas al aumento de la oferta, no modifica las dinámicas inequitativas acerca del acceso del agua, como procesos envueltos en la gestión y demanda del recurso en el territorio chileno. Además, la naturalización de la escasez impide involucrar todos los actores en el territorio en la búsqueda/elaboración de soluciones integrales y holísticas para así hacer frente al problema. Este paso requiere de la voluntad política por parte del Estado de hacer a la población afectada por la escasez a nivel local, partícipe de la planificación de las medidas, así como de las inversiones asociadas. Al mismo tiempo una gestión más integral del agua requiere la visibilización e integración de los consumos de agua de las bio-infraestructuras y priorizar el agua para el consumo humano. Asimismo, es necesario crear elementos político-normativos que reconozcan la hibridez de la escasez de agua y, por ende, se 
hagan cargo de sus orígenes sociales. Esto abre, además, la posibilidad de avanzar en la gestión integral, que vincula el agua con la sociedad y el territorio, y modifica las prioridades del uso del agua, resguardando su calidad y cantidad de externalidades negativas derivadas de las actividades antrópicas, tales como las actividades forestales, agrícolas, mineras, entre otras. De no ser así y si persiste la naturalización de la escasez de agua, sin reconocer sus causas sociales y políticas, además de las naturales o físicas, el problema de la escasez de agua en el país no tendrá solución y se verá agravada.

\section{Agradecimientos}

Se agradece a las personas e instituciones que colaboraron en brindar información, recursos y entrevistas durante los años 2011, 2012 y 2016. Así también, se reconocen y agradecen los apoyos financieros del Proyecto Anillo, SOC1404: Dinámicas naturales, espaciales y socio-culturales: perspectivas sobre los conflictos socio-ambientales en territorios forestales de Chile, 1975-2014. Director de Proyecto. 2015-2017, de la Universidad de Chile; al Heidelberg Center para América Latina - Centro de Excelencia en Investigación y Docencia de la Universidad de Heidelberg y al Deutscher Akademischer Austauschdienst (DAAD) de la República Federal de Alemania. Universidades donde la autora principal desarrolló su M. Sc. "Governance of Risk and Resources".

\section{Referencias bibliográficas}

ASHTON, P., Y NEAL, M. An Overview of Key Strategic Issues in the Okavango Basin. En A. A. Turton et al, Transbundary Rivers, Sovereignty and Development: Hydropolitical Drivers in the Okavango River Basin (págs. 31-63). Ginebra: Green Cross International, 2003.

BACHELET, M. Discurso de S.E. La Presidenta de la República, Michelle Bachelet, al anunciar plan nacional en la perspectiva de asegurar el agua para Chile, 2015. Disponible en internet: https:// www.google.cl/\#q=DISCURSO+DE+S.E.+LA+PRESIDENTA+DE+LA+REP\%C3\%9ABLICA\%2C+MI$C H E L L E+B A C H E L E T \% 2 C+A L+A N U N C I A R+P L A N+N A C I O N A L+E N+L A+P E R S P E C T I V A+D E+A S E G U-$ RAR+EL+AGUA+PARA+CHILE

BARTON, J. Climate Change Adaptive Capacity in Santiago de Chile: Creating a Governance Regime for Sustainability Planning. In: International Journal of Urban and Regional Research 37 (6): 1916-1933, 2013.

BAUER, C. Results of Chilean water markets: Empirical research since 1990. Water Resources Research, 40 (9), 2004.

BAUER, C.J. Water conflicts and entrenched governance problems in Chile's market model. Water Alternatives, 8(2): 147-172, 2015.

BUCHS, A. Water crisis and water scarcity as social constructions. The case of water use in Almería (Andalusia, Spain). Options Méditerranéennes: Série A. Séminaires Méditerranéens, № 95, $207-$ 211, 2010. 
BUDDS, J. Contested H2O: Science, policy and politics in water resources management in Chile. Geoforum 40, 418-430, 2009.

BUDDS, J. La demanda, evaluación y asignación del agua en el contexto de escasez: un análisis del ciclo hidrosocial del valle del río La Ligua, Chile. Revista de Geografía Norte Grande, № 52, $167-$ 184, 2012.

BUDDS, J. Water, power, and the production of neoliberalism in Chile, 1973-2005. Environment and Planning D: Society and Space, 31: $301-318,2013$.

CENSO NACIONAL DE POBLACIÓN Y VIVIENDA. Chile, 2002.

CÓDIGO DE AGUAS. Fija Texto del Código de Aguas. Ministerio de Justicia, Chile. Versión 4 de septiembre, 2014.

CONAF. Estadísticas Forestales. Plantaciones Forestales: Superficie Regional Forestada y Reforestada. Región de Los Ríos: Superficie forestada y reforestada por provincia, comuna y año (ha). 2007-2014. 2016. Disponible en internet: http://www.conaf.cl/nuestros-bosques/bosques-en-chile/estadisticas-forestales/

CONAF. Información de bonificaciones al fomento Forestal de la comuna de La Unión entre los años 2000 y 2014. Mediante Ley de Transparencia N²0.285, entrega 25 de noviembre, 2016 b.

COOLEY ET AL., Global Water Governance in the Twenty-First Century. En P. (Gleick, The World's Water Volume 8; the biennial report on freshwater resources.

Centro de Ciencia del Clima y la Resiliencia (CR2). (2015). Informe a la Nación. La megasequía 2010-2015: Una lección para el futuro. p.28, 2014.

CENTRO DE CIENCIA DEL CLIMA Y LA RESILIENCIA (CR)2. Informe a la Nación. La mega sequía 2010-2015: Una lección para el futuro. Universidad de Chile. Universidad Austral. Universidad de Concepción, 2015.

DIRECCIÓN GENERAL DE AGUAS (DGA). Decreto Numero 1674 sobre criterios para calificar épocas extraordinarias de sequía, 2012.

DIRECCIÓN GENERAL DE AGUAS (DGA). Atlas del Agua Chile 2016. Capitulo II, Nuestra Agua. p.2487, 2016.

DIRECCIÓN DE OBRAS HIDRÁULICAS (DOH). Listado oficial de sistemas de agua potable rural de la comuna de La Unión, Región de Los Ríos, Chile. Mediante Ley de Transparencia 20.285, 2016.

DONOSO, G. Análisis del funcionamiento del mercado de los derechos de aprovechamiento de agua e identificación de sus problemas. Rev. Derecho Admin. Econ., 1(2): 295- 314.

ESPARZA, M. La sequía y la escasez de agua en México. Situación actual y perspectivas futuras Secuencia. Revista de historia y ciencias sociales, N89. 193-219, 2014. 
ESQUIVEL, E. Lluvia y sequía en el norte de México. Un análisis de la precipitación histórica en Chihuahua. Gaceta Ecológica, Nº65. 24-42, 2002.

FAO/MINISTERIO DE AGRICULTURA. Inventario de Instrumentos de fomento y medidas de emergencia para la gestión del riesgo agroclimático, 2011. Disponible en internet: http://www.fao.org/3/a-as430s.pdf

FEITELSON, E., Y CHENOWETH, J. Water Poverty: towards a meaningful indicator. Water Policy, Vol. 4, No3, p. 263-281, 2002.

FRENE, C. Y NÚÑEZ, M. Hacia un nuevo Modelo Forestal en Chile. Revista Bosque Nativo 47: 25 35, 2010.

GONZÁLEZ, A. Y MUÑOZ, A. Cambios en la precipitación de la ciudad de Valdivia (Chile) durante los últimos 150 años. BOSQUE 34(2): 191-200, 2013.

HARVEY, D. Espacios del capital. Hacia una geografía crítica. Madrid: Urbanismo y desigualdad social. Siglo XXI (2007a), 1985.

HUBER, A.; IROUME, A. Y BATHURST, J. Effect of Pinus radiata plantation on water balance in Chile. Hydrological Processes, N²2, 142-148, 2008.

IROUMÉ A.; PALACIOS H.; BATHURST J. AND HUBER A. Escorrentías y caudales máximos luego de la cosecha a tala rasa y del establecimiento de una nueva plantación en una cuenca experimental del sur de Chile. Revista BOSQUE 31(2): 117-128, 2010.

INFOR. El sector forestal chileno 2015. Disponible en internet: http://wef.infor.cl/sector_forestal/ sectorforestal.php\#/2

INSTITUTO NACIONAL DE DERECHOS HUMANOS (INDH). Informe sobre el proyecto de ley que extiende la bonificación establecida en el decreto ley $N^{\circ} 701$, de 1974, sobre fomento forestal, cuyo texto fue reemplazado por el artículo primero del decreto ley $N^{\circ} 2565$, de 1979 . Boletín $N^{\circ} 10064$ 01, 2015.

KAIKA, M. Constructing scarcity and sensationalising water politics: 170 days that shook Athens. Antipode, Vol. 35, N5, pp. 919-54, 2003.

LARA A.; LITTLE C.; URRUTIA R.; MCPHEE J.; ALVAREZ C.; OYARZUN C.; SOTO D.; DONOSO P.; NAHUELHUAL L.; PINO M. AND ARISMENDI I. Assessment of ecosystem services as an opportunity for the conservation and management of native forests in Chile. Forest Ecology and Management 258 (2009) 415-424.

LARSON, A. Y SOTO, F. Decentralizatión of Natural Resource Governance Regimes. Annual Review of Environment and Resources 33: 213-239, 2008.

LINTON, J. Y BUDDS, J. The hydrosocial cycle: Defining and mobilizing a relational-dialectical approach to water. Journal Geoforum, № 57. 170-180, 2014. 
LITTLE C.; LARA, A. Y URRUTIA, R. Revealing the impact of forest exotic plantations on water yield in large scale watersheds in South-Central Chile. Journal of Hydrology, N 374, 162-170, 2009.

MÁÑEZ ET AL. Water resources in coastal areas - scarcity and management implications. En J. A. Wiedling, Recent Impluses to Marine Science and Engineering. Between space and sea floor (págs. 15-17). YOUMARES 3 a joint convention of the German Society for Marine Research and Fraunhofer EMB, 2012.

MARCOS, O. Sequía: definiciones, tipologías y métodos de cuantificación. Investigaciones Geográficas, N²6. 59-80, 2001.

MASCAREÑO, A. Social coordination through public policies: the Chilean case. In: Cepal Review 101: 107-122, 2010.

MEHTA, L. The Manufacture of Popular Perceptions of Scarcity: Dams and Water-Related Narratives in Gujarat, India. World Development, Vol. 29, №12. 2025-2041, 2001.

MEHTA, L. Whose scarcity? Whose property? The case of water in western India. Land Use Policy, N²4. 654-663, 2007.

NÚÑEZ, J., RIVERA, D., OYARZÚN, R., ARUMÍ, J. L. Chile a secas: vulnerabilidad chilena frente a la sequía y déficit hídrico extremo desde la interfaz ciencia-política. Instituto de Políticas Públicas, Universidad Diego Portales. Facultad de Economía y Empresa, 2013.

OPPLIGER, A. Diagnóstico exploratorio de la problemática de escasez de agua de las localidades rurales afectadas ubicadas al oeste de la ciudad de La Unión, comuna homónima. Documento Técnico, Programa de Naciones Unidas para el Desarrollo (PNUD), Chile, 2011.

OPPLIGER, A. Bases para un proceso de gestión integrada en las microcuencas hidrográficas de Mashue, con énfasis en la producción de agua potable rural, comuna de La Unión, Región de Los Ríos. Tesis de Pregrado. Universidad de Chile, 2012.

OPPLIGER, A. Tipologías de escasez de agua: develando orígenes mediante el ciclo hidrosocial. Tesis de Master of Sciences. Universität Heidelberg, 2016.

PALOMINO-SCHALSCHA, M., LEAMAN-CONSTANZO, C., \& BOND, S. Contested water, contested development: unpacking the hydro-social cycle of the Nuble River, Chile. In: Third World Quarterly, 37 (5), 883-901, 2016.

PARDO, N. Análisis crítico del discurso: conceptualización y desarrollo. Cuadernos de Lingüística Hispánica Nº19, 41-62, 2012.

PLADECO (2011). Actualización Plan de Desarrollo Comunal 2011-2014.

PNUD Beyond scarcity: Power, poverty and the global water crisis. New York. USA, 2006. 
PRIETO, M. La ecología (A)política del modelo de aguas chileno. En B. Bustos, \& M. y. Prieto, Ecología política en Chile: Naturaleza, propiedad, conocimiento y poder, 2015.

MESA DEL AGUA, M. Primera Acta de Reunión del Subcomité de Asuntos Hídricos. Provincia del Ranco, Región de Los Ríos, Chile. 28 de marzo y 23 de mayo, 2016.

RIJSBERMAN, F. Water scarcity: fact or fiction?. Agricultural Water Management, №80. 5-22, 2006.

SWYNGEDOUW, E.; KAÏKA, M. Y CASTRO, E. Urban Water: A Political-Ecology Perspective. Built Environment (1978-), Vol. 28, No. 2, Water Management in Urban Areas (2002), pp. 124-137, 2002.

SWYNGEDOUW, E. Y HEYNEN, N. Urban political ecology, justice and political of scale. Editorial Board of Antipode. Published by Blackwell Publishing, 9600 Garsington Road, Oxford OX4 2DQ, UK and 350 Main Street, Malden, MA 02148, USA. pp.898-918, 2003.

SWYNGEDOUW, E. The Political Economy and Political Ecology of the Hydro-Social Cycle. Journal of Contemporary Water Research \& Education Issue 142, 56-60, 2009.

SWYNGEDOUW E. UN Water Report 2012: Depoliticizing Water. Development and Change 44(3): 823-835, 2013.

SWYNGEDOUW E., "Not A Drop of Water...": State, Modernity and the Production of Nature in Spain, 1898-2010. The White Horse Press. Environment and History 20. 67-92., 2014.

SZIGETI, C. Reformas constitucionales en materia de aguas y reformas al Código de Aguas. Documento de Trabajo. Santiago: Chile Sustentable, 2013.

TORRES-SALINAS ET AL., Forestry development, water scarcity, and the Mapuche protest for environmental justice in Chile. Ambiente y Sociedad XIX (1): 121-144, 2016.

WOLFE, S., Y BROOKS, D. Water scarcity: An alternative view and its implications for policy and capacity building. Natural Resources Forum, №27. 99-107, 2003. 
